\title{
EFEITO DE ENZIMAS FIBROLÍTICAS SOBRE A DEGRADAÇÃO MICROBIANA RUMINAL DA FIBRA DE CANA-DE-AÇÚCAR
}

\author{
Emilio Manuel Aranda Ibáñez, ${ }^{1}$ Germán David Mendoza Martínez, ${ }^{2}$ Jesús Alberto Ramos Juárez, ${ }^{3}$ \\ Ives Cláudio da Silva Bueno ${ }^{4}$ e André César Vitti ${ }^{5}$ \\ 1. Engenheiro bioquimico, mestre em Ciência da Nutrição Animal, doutor em veterinária UNAM, Mexico, profesor investigador asociado \\ Colegio Postgraduados Mexico, niembro Sistema Nacional de Investigadores Conacyt Mexico Nivel I. E-mail: earanda@colpos.mx \\ 2. Universidad Autonoma Metropolitana \\ 3. Campus Tabasco Colegio de Postgraduados \\ 4. Agência Paulista de Tecnologia dos Agronegócios, Polo Centro Sul \\ 5. Agência Paulista de Tecnologia dos Agronegócios, Polo Centro Sul.
}

\section{RESUMO}

Com o objetivo de estudar os limitantes da degradação da fibra da cana-de-açúcar para utilizá-la como alimento para bovinos, fracionaram-se os componentes fibrosos da cana-de-açúcar (variedade Mex69-290) em fibra em detergente neutro (FDN) e em fibra em detergente ácido (FDA). A cana integral e as fibras foram incubadas com bactérias ruminais, na presença ou ausência de enzimas fibrolíticas (Fibrozyme, Alltech Inc.). Determinaramse o crescimento microbiano e as bactérias totais, assim como a taxa de crescimento, a taxa de geração, o tempo de colonização e a degradabilidade. Os resultados foram analisados em um delineamento de blocos ao acaso, com arranjo fatorial $2 \times 3$, com duas doses de enzima e três substratos, utilizando quatro repetições de incubação. Observou-se o maior crescimento microbiano para cana integral e os menores para suas fibras. A degradabilidade in vitro foi de 0,701, 0,392 e 0,191, respectivamente para cana integral, FDN e FDA $(\mathrm{P}<0,01)$. A fração FDA com a adição das enzimas fibrolíticas teve sua degradabilidade aumentada de 0,387 para 0,425 $(\mathrm{P}<0,01)$. O crescimento microbiano foi limitado nas frações fibrosas, possivelmente pelo grau de lignificação das paredes celulares. A maior degradabilidade in vitro das frações fibrosas está associada à presença de açúcares solúveis. A adição de enzimas fibrolíticas aumentou o crescimento microbiano máximo e a digestibilidade da FDA, indicando que estas podem ser um potencial aditivo para melhorar o aproveitamento de dietas com cana-de-açúcar.

PALAVRAS-CHAVES: Crescimento microbiano, degradabilidade in vitro, parede celular.

\section{ABSTRACT}

\section{EFFECT OF FIBROLITIC ENZYMES ON RUMEN MICROBIAL DEGRADATION OF SUGARCANE FIBER}

Aiming to study the limiting factors for degradation of sugarcane fiber to be used as cattle feed, sugarcane fibrous components were fractioned in neutral- and acid-detergent fibers (respectively, NDF and ADF). Whole sugarcane and its fibers were incubated with rumen bacteria, in presence or absence of fibrolytic enzymes (Fibrozyme, Alltech Inc.). Microbial growth and total bacteria count were determined, and the growth rate, generation rate, lag time, and degradability were also determined. Results were analyzed in randomized block design, with a $2 \times 3$ factorial arrangement, with two doses of enzymes, and three substrates, using four replications for incubation. The highest microbial growth

KEYWORDS: Cell wall, in vitro degradability, microbial growth. was observed for whole sugarcane, and the lowest for its fibers. The in vitro degradability was $0.701,0.392$ and 0.191 , respectively for whole sugarcane, NDF and $\mathrm{ADF}(\mathrm{P}<0.01)$. ADF fraction with the addition of fibrolytic enzyme had its degradability increased from 0.387 to $0.425(\mathrm{P}<0.01)$. Microbial growth was limited in fibrous fractions, possibly due to lignification grade of cell walls. The highest in vitro degradability of fibrous fractions is related to the presence of soluble sugars. Addition of fibrolytic enzymes increased the maximum microbial growth and ADF degradability, indicating that it could be a potential addictive to enhance diets containing sugarcane. 


\section{INTRODUÇÃO}

Os principais limitantes da utilização da canade-açúcar (Saccharum officinarum L.) na alimentação de ruminantes são a baixa digestibilidade de sua parede celular, o elevado teor de açúcares e a estrutura das moléculas das paredes celulares (LOPEZ et al., 2003; ARANDA et al., 2004). GÓMEZ-VAZQUEZ et al. (2003) notaram uma resposta linear na digestibilidade da fibra em detergente neutro (FDN) e no ganho de peso dos novilhos alimentados com pasto estrela e cana-de-açúcar, ao receber doses crescentes de uma enzima fibrolítica exógena. O objetivo deste trabalho foi estudar o efeito da adição de enzimas fibrolíticas exógenas sobre o crescimento microbiano e sobre a fermentação ruminal da cana-de-açúcar, sob a hipótese de que as enzimas fibrolíticas podem incrementar a digestibilidade das paredes celulares da cana-de-açúcar, assim como melhorar a eficiência da fermentação ruminal e estimular o crescimento microbiano.

\section{MATERIAL E MÉTODOS}

Foram realizadas incubações in vitro de canade-açúcar integral, variedade Mex69-290 (Quadro 1), assim como de suas frações fibrosas extraídas com detergentes neutro e ácido (respectivamente FDN e FDA) (VAN SOEST et al., 1991) com ou sem a adição da enzima fibrolítica Fibrozyme (Alltech Inc.), na dose de $100 \mathrm{mg} / \mathrm{g}$ de substrato incubado (PINOS, 1999).

QUADRO 1. Composição da cana-de-açúcar, variedade Mex69290, com doze meses de vegetação

\begin{tabular}{|l|c|}
\hline \multicolumn{1}{|c|}{ Composição } & Teor (\%) \\
\hline Matéria seca (MS) & 31,90 \\
\hline Proteína bruta (PB) & 2,53 \\
\hline Conteúdo celular & 39,50 \\
\hline Fibra em detergente neutro (FDN) & 60,50 \\
\hline Hemicelulose & 15,64 \\
\hline Fibra em detergente ácido (FDA) & 44,86 \\
\hline Lignina em detergente ácido (LDA) & 6,72 \\
\hline${ }^{\circ}$ Brix & 16,40 \\
\hline
\end{tabular}

Calcularam-se a taxa de crescimento com base na regressão do logaritmo natural da concentração de bactérias em função do tempo e a taxa da geração mediante a relação $0,693 / \mathrm{k}$, sendo $\mathrm{k}$ a taxa específica de crescimento ou o coeficiente de manutenção da relação inversa da concentração das bactérias, no tempo zero (PIRT, 1982). O tempo de colonização (fase lag) foi estimado como inverso dos valores do crescimento por extrapolação ao tempo zero (ZWIETERING et al., 1991). Estimaram-se os parâmetros por regressão (DRAPPER \& SMITH, 1981).

Em erlenmeyers de capacidade de $250 \mathrm{~mL}$, foram colocados $150 \mathrm{~mL}$ de meio anaeróbio (Quadro 2), $1 \mathrm{~mL}$ de líquido ruminal e $100 \mathrm{mg}$ de substrato incubados em saco de nylon, medindo $4 \times 5 \mathrm{~cm}$, por 24 horas à temperatura constante de $39^{\circ} \mathrm{C}$. Para isso, utilizaram-se dez réplicas por amostra, com e sem a adição de enzima fibrolítica. Ao final da incubação, os sacos foram secos a $65^{\circ} \mathrm{C}$, até peso constante. Considerou-se a diferença entre os pesos inicial e final das amostras como material degradado e calculou-se a degradabilidade como a razão entre o material degradado e o peso inicial.

Seguindo a mesma metodologia, como descrito, incubaram-se as amostras com e sem enzima fibrolítica, com três réplicas, repetidas em cinco ensaios. $\mathrm{O}$ crescimento microbiano foi determinado em intervalos de trinta minutos nas primeiras dez horas, com uma leitura final às 25 horas, utilizando espectrofotômetro (Spectronic 20, Bausch and Lomb), ajustado para 600 nm, segundo RUSSEL \& DOMBROWSKI (1980). Empregou-se a contagem total de bactérias, para transformar o valor de densidade óptica em concentração de bactérias, visando caracterizar as curvas de crescimento (MIRANDA, 1998).

Os resultados foram analisados de acordo com um delineamento de blocos ao acaso (STEEL \& TORRIE, 1980), com arranjo fatorial $2 \times 3$, com dois teores de enzima e três substratos (cana integral e suas frações - FDN e FDA). Realizaram-se quatro repetições de incubação (CLARY et al., 1988). Usouse o seguinte modelo estatístico: $\mathrm{Y}_{\mathrm{ijk}}=\mu+\mathrm{B}_{\mathrm{j}}+\mathrm{S}_{\mathrm{i}}+$ $\mathrm{C}_{\mathrm{k}}+\mathrm{S}_{\mathrm{i}} * \mathrm{C}_{\mathrm{k}}+\mathrm{B}_{\mathrm{j}} * \mathrm{~S}_{\mathrm{i}} * \mathrm{C}_{\mathrm{k}}+\varepsilon_{\mathrm{ijk}}$, sendo $\mathrm{Y}_{\mathrm{ijk}}$ a variável resposta; $\mu$, a média geral; $\mathrm{B}_{\mathrm{j}}$, efeito do bloco; $\mathrm{S}_{\mathrm{i}}$, efeito do substrato; $\mathrm{C}_{\mathrm{k}}$, efeito da adição de enzima; $\mathrm{S}_{\mathrm{i}}{ }^{*} \mathrm{C}_{\mathrm{k}} \mathrm{e}$ $\mathrm{B}_{\mathrm{j}}{ }^{*} \mathrm{~S}_{\mathrm{i}} * \mathrm{C}_{\mathrm{k}}$, interações; e $\varepsilon_{\mathrm{ijk}}$, o erro residual do modelo. Empregou-se o procedimento GLM do SAS (1985), considerando-se a interação blocos $x$ tratamentos como 
o erro experimental. As médias foram comparadas pelo teste de Tukey (STEEL \& TORRIE, 1980).

QUADRO 2. Composição do meio anaeróbio utilizado para a estimativa das bactérias totais e celulolíticas.

\begin{tabular}{|c|c|c|}
\hline \multirow{2}{*}{ Composição } & $\begin{array}{c}\text { Meio } \\
\text { GCA-FR }\end{array}$ & $\begin{array}{c}\text { Meio } \\
\text { PW-FR }\end{array}$ \\
\hline & \multicolumn{2}{|c|}{ Quantidade $(/ 100 \mathrm{~mL})$} \\
\hline Extrato de levedura & 0,1 & 0,1 \\
\hline Tripticase-peptona & 0,2 & 0,2 \\
\hline Glucose & 60 & -- \\
\hline Celubiose & 60 & -- \\
\hline Amido & 60 & -- \\
\hline Solução mineral Ia & 5,0 & 5,0 \\
\hline Solução mineral II ${ }^{\mathrm{b}}$ & 5,0 & 5,0 \\
\hline Líquido ruminal clarificado & 30,0 & 30,0 \\
\hline Solução de cisteína-sulfidoc ${ }^{c}$ & 2,0 & 2,0 \\
\hline Solução de carbonato de sódio 8\% & 5,0 & 5,0 \\
\hline Resazurina $0,1 \%$ & 0,1 & 0,1 \\
\hline Água destilada & 52,6 & 52,6 \\
\hline Papel Whatman n. ${ }^{\circ} 1$ & --- & $\begin{array}{c}\text { Uma } \\
\text { camada }\end{array}$ \\
\hline
\end{tabular}

a $6 \mathrm{~g} \mathrm{~K}_{2} \mathrm{HPO}_{4} / 1000 \mathrm{~mL}$,

b $6.0 \mathrm{~g} \mathrm{KH}_{2} \mathrm{PO}_{4}, / 1000 \mathrm{~mL} ; 6.0 \mathrm{~g}\left(\mathrm{NH}_{4}\right)_{2} \mathrm{SO}_{4}, / 1000 \mathrm{~mL} ; 12 \mathrm{~g} \mathrm{NaCl}, / 1000$ $\mathrm{mL} ; 2.45 \mathrm{~g} \mathrm{MgSO}_{4} / 1000 \mathrm{~mL}$ e $1.6 \mathrm{~g} \mathrm{CaCl}_{2} \mathrm{H}_{2} \mathrm{O} / 1000 \mathrm{~mL}$.

c $2.5 \mathrm{~g} \mathrm{~L}$-cisteína ( $15 \mathrm{~mL}$ de $\mathrm{NaOH} 2 \mathrm{~N} ; 2.5 \mathrm{~g} \mathrm{Na}{ }_{2} \mathrm{~S} \cdot 9 \mathrm{H}_{2} \mathrm{O}$, )

GCA-FR = glucose, celubiose, amido e fluido ruminal

PW-FR = Papel Whatman e fluido ruminal.

\section{RESULTADOS E DISCUSSÃO}

Na Tabela 1 e na Figura 1, é apresentado o crescimento das bactérias ruminais de acordo com o substrato incubado.

Apesar de haver uma tendência de maior crescimento microbiano na cana integral, as diferenças estatísticas com respeito ao substrato foram observadas a partir das 3,5 horas. Nas primeiras horas de incubação, não houve diferenças significativas, possivelmente em virtude da grande variabilidade da absorbância, coincidindo com as observações de MERTENS (1993), que apontam que os trabalhos in vitro, em sua primeira etapa, apresentam alta variabilidade. O maior crescimento microbiano na cana integral se deve à presença de açúcares solúveis de fácil degradação (BANDA \&
VALDEZ, 1976), e o menor crescimento em FDA se associa ao alto teor de lignina (AMJED et al., 1992).

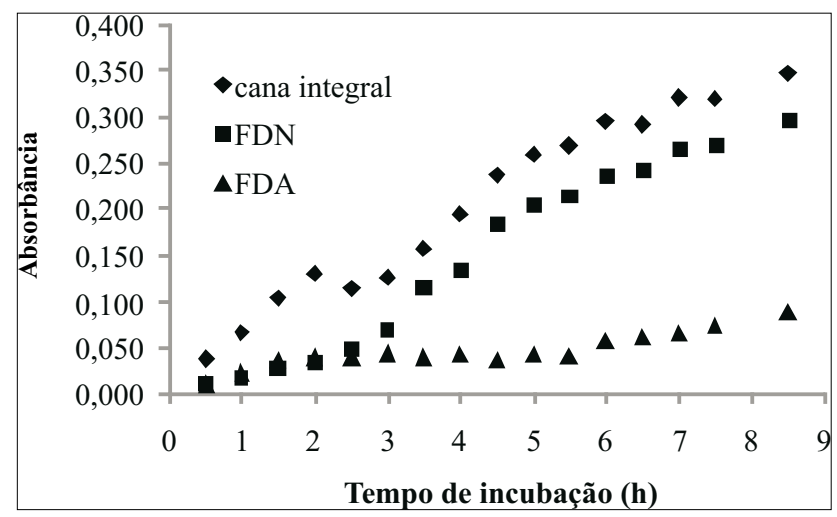

FIGURA 1. Crescimento de bactérias ruminais incubadas com cana-de-açúcar e suas frações fibrosas.

A resposta do crescimento microbiano mediante a adição de enzimas é apresentada nas Figuras 2, 3 e 4, sendo uma para cada substrato. Na Tabela 2, os principais efeitos são apresentados, e nela pode-se observar o maior crescimento microbiano em resposta à adição da enzima. Há uma resposta positiva à adição de enzimas fibrolíticas, indicando que há aumento da disponibilidade de metabólitos para o crescimento microbiano. A maior diferença foi observada na fração FDA (Figura 4), a qual poderia estar associada à maior degradabilidade devida à ação enzimática sobre as ligações ligno-celulósicas e possivelmente a outros efeitos indiretos. É possível que a adição de enzimas exógenas possa incrementar a fração potencialmente degradável da celulose contida na FDA (AKIN, 1986).

Na Tabela 3, são apresentados os parâmetros de crescimento microbiano na cana-de-açúcar. Apesar das diferenças apresentadas na Tabela 2, as diferenças estatísticas não são detectadas para os parâmetros do crescimento microbiano na cana-de-açúcar e em suas frações fibrosas. Esse problema foi detectado em análise de cinética de primeira ordem. MENDOZA et al. (1995) sugerem que os dados sejam analisados por tempo de incubação, dado que podem existir diferenças em alguns tempos de incubação, e a linearização com logaritmo natural altera o erro residual do modelo, não permitindo detectar estatisticamente algumas diferenças biologicamente importantes. 
TABELA 1. Crescimento microbiano (densidade óptica) de microrganismos ruminais incubados em cana-de-açúcar e suas frações fibrosas (FDN e FDA)

\begin{tabular}{ccccc}
\hline \multirow{2}{*}{ Tempo (h) } & & Substrato & E.P.M. \\
\cline { 2 - 4 } 0,5 & Cana-de-açúcar & FDN & FDA & 0,034 \\
\hline 1,0 & 0,060 & 0,037 & 0,040 & 0,040 \\
1,5 & 0,087 & 0,052 & 0,054 & 0,058 \\
2,0 & $-0,129$ & 0,068 & 0,074 & 0,070 \\
2,5 & 0,156 & 0,094 & 0,097 & 0,059 \\
3,0 & 0,148 & 0,099 & 0,088 & 0,066 \\
3,5 & 0,159 & 0,118 & 0,095 & 0,063 \\
4,0 & $0,200^{\mathrm{a}}$ & $0,155^{\mathrm{ab}}$ & $0,111^{\mathrm{b}}$ & 0,057 \\
4,5 & $0,240^{\mathrm{a}}$ & $0,169^{\mathrm{a}}$ & $0,121^{\mathrm{b}}$ & 0,048 \\
5,0 & $0,265^{\mathrm{a}}$ & $0,221^{\mathrm{a}}$ & $0,146^{\mathrm{b}}$ & 0,055 \\
5,5 & $0,293^{\mathrm{a}}$ & $0,159^{\mathrm{b}}$ & 0,046 \\
6,0 & $0,307^{\mathrm{a}}$ & $0,245^{\mathrm{a}}$ & $0,162^{\mathrm{b}}$ & 0,048 \\
6,5 & $0,333^{\mathrm{a}}$ & $0,252^{\mathrm{a}}$ & 0,182 & 0,055 \\
7,0 & $0,342^{\mathrm{a}}$ & $0,271^{\mathrm{b}}$ & 0,203 & 0,050 \\
7,5 & $0,361^{\mathrm{a}}$ & $0,294^{\mathrm{a}}$ & 0,212 & 0,051 \\
8,5 & $0,367^{\mathrm{a}}$ & $0,301^{\mathrm{a}}$ & 0,216 & 0,059 \\
\hline
\end{tabular}

E.P.M. = erro-padrão da média

ab Médias com sobrescritos distintos, nas linhas, diferem entre si (teste de Tukey; $\mathrm{P}<0,05$ ).

TABELA 2. Efeito da adição de enzimas fibrolíticas no crescimento microbiano (densidade óptica) ao incubar microrganismos ruminais com cana-de-açúcar

\begin{tabular}{cccc}
\hline Tempo $(\mathrm{h})$ & \multicolumn{2}{c}{ Tratamentos } & E.P.M. \\
\cline { 2 - 4 } & Sem enzimas & Com enzimas & 0,034 \\
\hline, 5 & $0,026^{\mathrm{b}}$ & $0,070^{\mathrm{a}}$ & 0,040 \\
1,0 & $0,042^{\mathrm{b}}$ & $0,093^{\mathrm{a}}$ & 0,058 \\
1,5 & $0,066^{\mathrm{b}}$ & $0,124^{\mathrm{a}}$ & 0,070 \\
2,0 & $0,081^{\mathrm{b}}$ & $0,162^{\mathrm{a}}$ & 0,059 \\
2,5 & $0,077^{\mathrm{b}}$ & $0,158^{\mathrm{a}}$ & 0,066 \\
3,0 & $0,091^{\mathrm{b}}$ & $0,170^{\mathrm{a}}$ & 0,063 \\
3,5 & $0,118^{\mathrm{b}}$ & $0,206^{\mathrm{a}}$ & 0,057 \\
4,0 & $0,142^{\mathrm{b}}$ & $0,229^{\mathrm{a}}$ & 0,048 \\
4,5 & $0,176^{\mathrm{b}}$ & $0,266^{\mathrm{a}}$ & 0,055 \\
5,0 & $0,194^{\mathrm{b}}$ & $0,290^{\mathrm{a}}$ & 0,046 \\
5,5 & $0,200^{\mathrm{b}}$ & $0,301^{\mathrm{a}}$ & 0,048 \\
6,0 & $0,223^{\mathrm{b}}$ & $0,323^{\mathrm{a}}$ & 0,055 \\
7,0 & $0,232^{\mathrm{b}}$ & $0,348^{\mathrm{a}}$ & 0,050 \\
7,5 & $0,246^{\mathrm{b}}$ & $0,359^{\mathrm{a}}$ & 0,051 \\
\hline
\end{tabular}

E.P.M. = erro-padrão da média

${ }^{\text {ab }}$ Médias com sobrescritos distintos, nas linhas, diferem entre si (teste de Tukey; $\mathrm{P}<0,05$ ). 


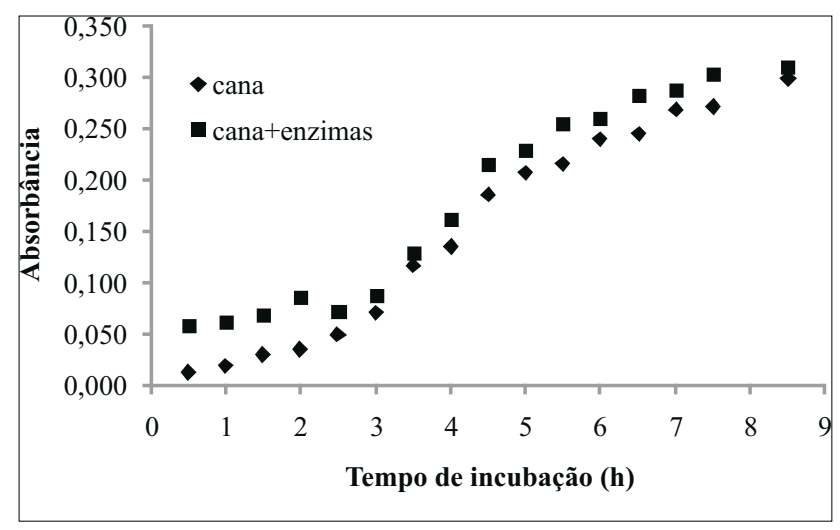

FIGURA 2. Crescimento de bactérias ruminais incubadas com cana-de-açúcar com ou sem enzimas fibrolíticas exógenas.

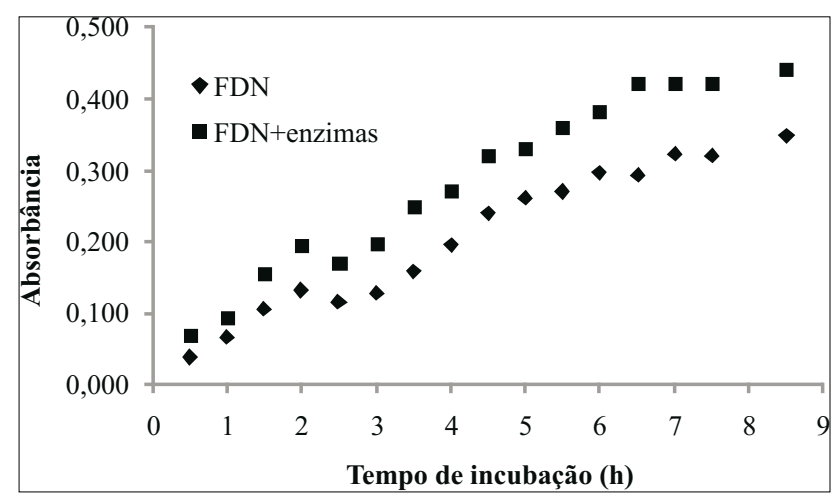

FIGURA 3. Crescimento de bactérias ruminais incubadas com FDN de cana-de-açúcar com ou sem enzimas fibrolíticas exógenas.

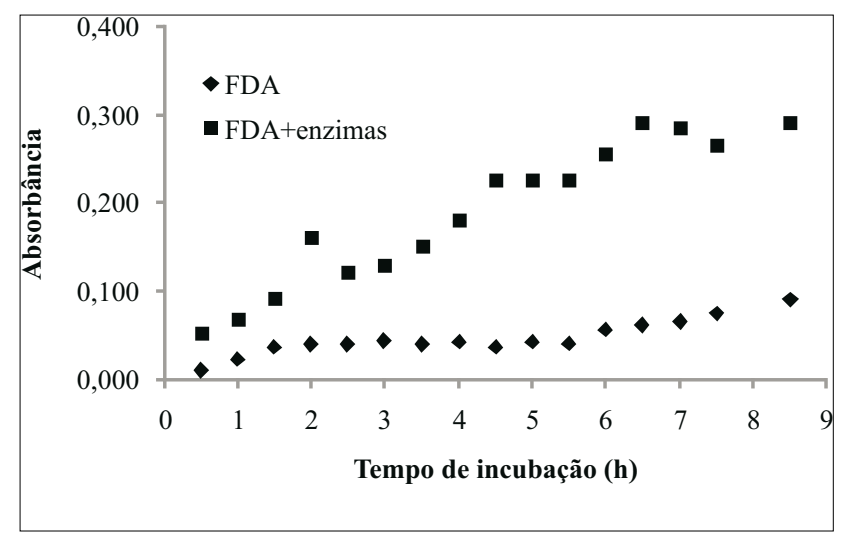

FIGURA 4. Crescimento de bactérias ruminais incubadas com FDA de cana-de-açúcar com ou sem enzimas fibrolíticas exógenas.

As taxas de crescimento e as taxas de geração foram similares para cana integral e para as frações FDN e FDA (Tabela 3). As taxas de crescimento observadas neste experimento são menores que as reportadas para cultivos mistos em substratos lignocelulósicos $(1,13 / \mathrm{h})$ como os restos da cultura de milho (MIRANDA et al., 1999). Os microrganismos celulolíticos $F$. succinogenes, $R$. flavefaciens e $R$. albus têm a capacidade de degradar a celulose a uma taxa entre 0,05 e 0,10/h (WEIMER, 1996). É possível inferir que a limitada taxa de crescimento na cana-de-açúcar é influenciada pela lignificação da fibra (Quadro 1) e pode ser o principal limitante para o aproveitamento da cana-de-açúcar, tornando necessária a busca de alternativas para aumentar a digestibilidade destas frações com tratamentos físicos, químicos, enzimáticos e biológicos. O tempo de colonização tendeu a ser maior na cana integral (Tabela 3 ). Tem sido reportados valores de 2,5 a 3,0 h de tempo de colonização em incubações com restos da cultura de milho com $70 \%$ de FDN (MIRANDA et al., 1999), os quais são menores que os observados neste estudo. A fase lag na FDA da cana-de-açúcar confirma a importância da lignina como limitante na digestão desse alimento.

TABELA 3. Características do crescimento microbiano e degradabilidade in vitro da cana-de-açúcar e suas frações fibrosas

\begin{tabular}{lcccc}
\hline & \multicolumn{3}{c}{ Substrato } & \\
\cline { 2 - 4 } Variáveis* $^{\text {Cana-de- }}$ & $\begin{array}{c}\text { Caçúcar } \\
\text { a.P.M. }\end{array}$ & FDN & FDA & \\
\hline $\mathrm{K}$ & 0,214 & 0,330 & 0,267 & 0,11 \\
$\mathrm{M}$ & 0,860 & 3,680 & 0,581 & 5,62 \\
$\mathrm{Lag}$ & 0,46 & 3,18 & 5,06 & 5,73 \\
Ymax & 3,11 & 1,68 & 2,17 & 1,39 \\
$\mathrm{k}_{0.5}$ & 3,53 & 2,50 & 2,98 & 1,14 \\
DIVMS & $0,701^{\mathrm{a}}$ & $0,302^{\mathrm{b}}$ & $0,191^{\mathrm{c}}$ & 0,038 \\
\hline
\end{tabular}

* k: taxa específica de crescimento (/h); m: coeficiente de manutenção; Ymáx: crescimento máximo; Lag: tempo de colonização $(\mathrm{h}) ; \mathrm{k}_{0.5}$ : taxa de geração (/h); DIVMS: degradabilidade in vitro da MS.

abc Médias com sobrescritos distintos, nas linhas, diferem entre si (teste de Tukey; $\mathrm{P}<0,05$ ).

A degradabilidade in vitro da cana-de-açúcar e suas frações fibrosas refletem a atividade microbiana e apontam os limitantes inerentes das paredes celulares para a digestão animal. A maior degradabilidade da cana-de-açúcar se deve à concentração de açúcares solúveis no conteúdo celular (BANDA \& VALDEZ, 1976; AROEIRA et al., 1993a; AROEIRA et al., 1993b). 
Apenas se observaram diferenças estatísticas na degradabilidade, sendo maior a da cana-de-açúcar, seguida por FDN e FDA. A degradabilidade in vitro da FDA observada neste estudo está dentro do intervalo de valores reportados (PATE, 1977) e coincide com a FDN potencialmente degradável reportada para subprodutos da cana (AMJED et al., 1992) associada à relação linear negativa entre a degradabilidade in vitro da FDN e a proporção FDN:lignina (PATE, 1977). A menor degradabilidade da FDA confirma a importância da lignina como limitante no aproveitamento da cana pelos microrganismos ruminais.

$\mathrm{Na}$ Tabela 4, são apresentados os principais efeitos das enzimas fibrolíticas nos parâmetros de crescimento microbiano e na degradabilidade in vitro. A adição da enzima aumentou a degradabilidade dos substratos em 3,81 unidades percentuais, o que pode ser a explicação do maior crescimento microbiano máximo, sem afetar outros parâmetros do crescimento. Tem sido reportados aumentos na degradabilidade in vitro da MS, da FDN e da FDA de gramíneas e leguminosas com a adição da enzima Fibrozyme (FENG et al., 1996; TRICARICO et al., 1998; PINOS et al., 2001; PINOS et al., 2002a; PINOS et al., 2002b) e mesmo na digestibilidade in vivo (KRAUSE et al., 1988; BEAUCHEMIN et al., 1998). No entanto, os resultados têm sido muito variáveis, possivelmente em virtude da razão enzima:substrato e da degradação da enzima por proteases ruminais (HARRIS, 1998).

As enzimas utilizadas são uma combinação de celulases e hemicelulases produzidas por fungos, protegidas por glicosilação, e estima-se que podem permanecer ativas por volta de doze horas no rúmen (HARRIS, 1998; LYONS, 1998). PINOS (1999) estudou a composição e a degradação ruminal in vitro da enzima Fibrozyme e reportou que o complexo tem 93,6\% de MS, $45,8 \%$ de FDN, 32,5\% de FDA e 9,5\% de cinzas, encontrando um tempo médio de degradação do complexo de 57 horas, com uma maior liberação de nitrogênio amoniacal depois de 24 horas.

O uso de enzimas microbianas celulolíticas exógenas para incrementar a digestibilidade da fibra da cana-de-açúcar é uma alternativa viável, como mostram os resultados de GÓMEZ-VÁSQUEZ et al. (2003). Também alguns estudos com gramíneas e leguminosas de clima temperado têm mostrado que, com a aplicação de enzimas fibrolíticas, podem ser melhorados a digestibilidade e o crescimento de novilhos em cerca de 30\% (BEAUCHEMIN et al., 1996) e a produção de leite em até 10\% (BEAUCHMIN et al., 1998; KUNG et al., 1998; YANG et al., 1998). Juntamente com o conhecimento das estruturas da parede celular da cana-de-açúcar e das enzimas industriais, é possível desenvolver novas alternativas de tratamentos para melhorar o aproveitamento da celulose e da hemicelulose pelos ruminantes.

TABELA 4. Efeito da adição de enzimas fibrolíticas no crescimento microbiano e na degradabilidade in vitro da cana-de-açúcar

\begin{tabular}{lccc}
\hline \multirow{2}{*}{ Variáveis } & \multicolumn{2}{c}{ Tratamento } & \multirow{2}{*}{ E.P.M. } \\
\cline { 2 - 3 } & Sem enzimas & Com enzimas & \\
\hline $\mathrm{K}$ & 0,317 & 0,228 & 0,11 \\
$\mathrm{M}$ & 2,97 & 0,647 & 5,62 \\
$\mathrm{Lag}$ & 3,340 & 8,314 & 5,73 \\
Ymáx & $1,549^{\mathrm{b}}$ & $3,038^{\mathrm{a}}$ & 1,39 \\
$\mathrm{k}_{0.5}$ & 2,736 & 3,253 & 1,13 \\
DIVMS & $0,387^{\mathrm{a}}$ & $0,425^{\mathrm{b}}$ & 0,021 \\
\hline
\end{tabular}

* k: taxa específica de crescimento (/h); m: coeficiente de manutenção; Ymáx: crescimento máximo; Lag: tempo de colonização (h); $\mathrm{k}_{0.5}$ : taxa de generação (/h); DIVMS: degradabilidade in vitro da MS.

${ }^{a b}$ Médias com sobrescritos distintos, nas linhas, diferem entre si (teste de Tukey; $\mathrm{P}<0,05)$.

\section{CONCLUSÕES}

O crescimento microbiano a partir da degradação da cana-de-açúcar é limitado pelas frações fibrosas, possivelmente pelo grau de lignificação das paredes celulares. A maior degradação in vitro da cana-de-açúcar em relação às suas frações fibrosas está associada à presença de açúcares solúveis.

A adição de enzimas fibrolíticas aumentou o crescimento bacteriano máximo e a degradabilidade da FDA, podendo-se concluir que é possível considerar as enzimas fibrolíticas como um aditivo potencial para melhorar o aproveitamento de dietas com cana-de-açúcar.

\section{REFERÊNCIAS}

AKIN, D. E. Interactions of ruminal bacteria and fungi with southern forages. Journal of Animal Science, v. 63, p. 962-977, 1986. 
AMJED, M.; JUNG, H. G.; DONKER, J. D. Effect of alkali hydrogen peroxide treatment on cell wall composition and digestion kinetics of sugarcane residues and wheat straw. Journal of Animal Science, v. 70, p. 2877-2884, 1992.

ARANDA, E. M.; RUIZ, P.; MENDOZA, G. D.; MARCOFF, C. F.; RAMOS, J. A.; Y ELÍAS A. Cambios en la digestión de tres variedades de caña de azúcar y sus fracciones de fibra. Revista Cubana de Ciencia Agrícola, Tomo 38, n. 2, p. 137-144, 2004.

AROEIRA, R. S.; FIGUEIRA, D. G.; RODRIGUEZ, N. M.; SAMPAIO, I. B. M.; LOPES, F. C.; TORRES, E. M. P. Degradabilidade in situ dos nutrientes da cana-de-açúcar e do farelo de algodão em bovinos alimentados com farelo de algodão e cana-de-açúcar de três níveis de uréia. Arquivo Brasileira de Medicina Veterinária Zootecnia, v. 45, p. 221-233, 1993 b.

AROEIRA, R. S.; LIZIEIRE, R. S.; MATOS, L. L.; FIGUEIRA, D. G. Rumen degradability and rate of passage of sugar cane + urea based diets, supplemented with cottonseed or rice meals in Holstein x Zebu steers. Journal of Animal Science, v. 71 (supp.1), p. 273, 1993a.

BANDA, M.; VALDEZ, R. E. Efecto del estado de madurez sobre el valor nutritivo de la caña de azúcar. Produção Animal nos Trópicos, v. 1, p. 96-99, 1976.

BEAUCHEMIN, K. A.; RODE, L. M.; SEWALT, V. J. H. Fibrolitic enzimes increase fiber digestibility and growth rate steers fed dry forages. Canadian Journal of Animal Science, v. 75, p. 641-644, 1996.

BEAUCHEMIN, K. A.; YANG, W. Z.; RODE, L. M. Effects of fibrolytic enzyme additives on extent of digestion and milk production of lactating cows. Journal of Animal Science, v. 76 (Suppl. 1), p. 358, 1998.

CLARY, W. P.; WELCH, B. L.; BOOTH, G. D. In vitro digestion experiments: importance of variation between inocula donors. Journal of Wildlife Management, v. 52, p. 358-361, 1988.

DRAPPER, N.; SMITH, H. Applied regression analysis. New York: John Wiley \& Sons, 1981. 709 p.

FENG, P. C.; HUNT, W.; PITCHARD, G. T.; JULIEN, D. W. E. Effect of enzyme preparations on in situ and in vitro digestive characteristics of mature cool-season grass forage in beef steers. Journal of Animal Science, v. 74, p. 1349-1357, 1996.

GOMEZ-VAZQUEZ, A.; PÉREZ, J.; MENDOZA, G. D.; ARANDA, E.; HERNÁNDEZ, A. Fibrolytic exogenous enzymes improve perfomance in steers fed sugar cane stargrass. Livestock Production Science, v. 82, p. 249-254, 2003.

HARRIS, B. The emerging role of enzymes in ruminant diets: at long last, a breakthrough. Udder Information. Dr. Harri's
Guide to Maximizing Dairy Performance. 1998. Disponível em: <http://www.alltech-bio.com/udder98.htm.pp1-13.> Acesso em: 12 jun. 2006.

KRAUSE, M.; BEAUCHEMIN, K. A.; RODE, L. M.; FARR, B. I.; NORGAARD, P. Fibrolytic enzyme treatment of barley grain and source of forage in high-grain diets fed to growing cattle. Journal of Animal Science, v. 76, p. 2912-2920, 1988.

KUNG, L.; TREACHER, R. J.; COHEN, M. A. Enzyme-treated forages for lactating cows. Journal of Animal Science, v. 76 (Suppl. 1), p. 196, 1998.

LYONS, T. P. The consumer is king: where sill it all end for the deed industry. In: LYONS, T. P.; JACQUES, K. A. (Eds.). Biotechnology in the feed industry. Proceedings of the Fourteenth Annual Symposium. Loughborough: Nottingham University Press, 1998. p. 3-29.

MENDOZA, M. G. D.; RICALDE, V. R.; ESPARZA, H. B.; VELAZQUEZ, Y. L. T. Nota: Efecto de dos cultivos de Saccharomyces cerevisiae en la degradacion ruminal de la fibra neutro detergente de paja de trigo. Investigación Agricola, Producción y Sanidade Animales, v. 10, p. 33-38, 1995.

MERTENS, D. M. Kinetics of cell wall digestion and passage in ruminants. In: JUNG, H. G.; BUXTON, D. R.; HATFIELD, R. D.; RALPH, J. ASA-CSSA-SSSA, 677S. Forage cell wall structure and digestibility. Madison, USA: Segoe RD. 1993. p. 535-571.

MIRANDA, R. L. A.; COBOS, M. A. P.; MENDOZA, M. G. D.; GONZÁLEZ, M. S. S.; GARCÍA, B. C. M. Degradación in vitro de rastrojo de maíz con cultivos mixtos de bacterias ruminales. Agrociencia, v. 33, n. 2, p. 133-139. 1999.

PATE, F. M. Nutritive value of sugar cane at different stages of maturity. Tropical Animal Production, v. 2, p. 108-109, 1977.

PINOS-RODRÍGUEZ, J. M.; GONZÁLEZ-MUÑOZ, S. S.; MENDOZA-MARTÍNEZ, G. D.; BÁRCENA-GAMA R.; COBOS-PERALTA. M. Efecto de enzimas fibrolíticas glucosiladas en la digestibilidad in vitro de MS y MO de alfalfa (Medicago sativa) y ballico (Lolium perenne). Revista Científica, FCV-LUZ v. 11, n. 6, p. 505-509. 2001.

PINOS-RODRÍGUEZ, J. M.; GONZÁLEZ-MUÑOZ, S. S; MENDOZA-MARTÍNEZ, G. D.; BÁRCENA-GAMA R.; COBOS-PERALTA, M. Efecto de enzimas fibrolíticas exógenas en la digestibilidad in vitro de la pared celular del heno de alfalfa (Medicago sativa) o de ballico (Lolium perenne). Interciencia, $\mathrm{v}$. 27 , n. 1 , p. 28-32. 2002 a.

PINOS-RODRÍGUEZ, J. M.; GONZÁLEZ-MUÑOZ, S. S.; G.D. MENDOZA, G. D.; R. BÁRCENA, R.; COBOS, M. A.; HERNÁNDEZ, A.; ORTEGA, M. E. Effect of exogenous fibrolytic enzyme on ruminal fermentation and digestibility of alfalfa and 
rye-grass hay fed to lambs. Journal of Animal Science, v. 80, n. 11, p. 3016-3020. 2002b.

PIRT, S. J. Maintenance energy: a general model for energy-limited and energy-sufficient growth. Archives of Microbiology, v. 133, p. 300-302, 1982.

LÓPEZ, I.; ARANDA, I. E. M.; RAMOS, J. J. A; MENDOZA, M. G. D. Evaluación nutricional de ocho variedades de caña de azúcar con potencial forrajero. Revista Cubana Ciencia Agricola, v. 37, p. 381. 2003.

RUSSELL, J. B.; DOMBROWSKI, D. B. Effect of $\mathrm{pH}$ on the efficiency of growth by pure cultures of rumen bacteria in continuous culture. Applied Environmental Microbiology, v. 39, p. 604-610, 1980.

STATISTICAL ANALYSIS SYSTEM. S.A.S. User's Guide: statistics version. 5. ed. Cary: SAS Institute Inc., 1985.

STEEL, R. G. D.; TORRIE, J. H. Principles and procedures of statistics: a biometrical approach. 2. ed. New York: McGraw-Hill Book Co., 1980. 633 p.
TRICARICO, M.; DAWSON, K. A.; NEWMAN, K. E. Effects of an exogenous microbial enzyme preparation (Fibrozyme) on ruminal digestion of fescue hay. Journal of Animal Science, v. 76 (Suppl. 1), p. 289, 1998.

VAN SOEST, P. J.; ROBERTSON, J. B.; LEWIS, B. A. Symposium: carbohydrate methodology, metabolism, and nutritional implications in dairy cattle. Journal of Dairy Science, v. 74, p. 3583-3597, 1991.

WEIMER, P. J. Why don't ruminal bacteria digest cellulosa faster. Journal of Dairy Science, v. 79, p. 1496-1502, 1996.

YANG, W. Z.; RODE, L. M.; BEAUCHEMIN, K. A. Effects of fibrolitic enzyme additives on milk production of dairy cows. Journal of Animal Science, v. 76 (Suppl. 1), p. 320, 1998.

ZWIETERING, M. H.; DE KOOS, J. T.; HASENACK, B. E.; DE WIT, J. C.; VAN'T RIET, K. Modeling of bacterial growth as a function of temperature. Applied Environmental Microbiology, v. 7, p. 1094-1101, 1991. 